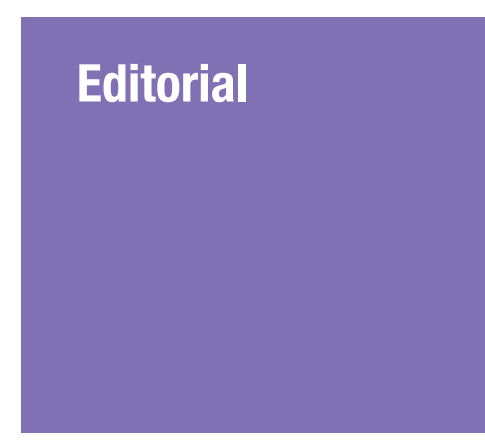

Submitted: 1 Nov 2016 Accepted: 5 Dec 2016 Online: 24 Feb 2017

\title{
We Must Invest in Applied Knowledge of Computational Neurosciences and Neuroinformatics as an Important Future in Malaysia: The Malaysian Brain Mapping Project
}

\author{
Putra Sumari ${ }^{1,3,}$ ZAmZURI Idris ${ }^{3,4,}$ JAFRI MaLIN Abdullah ${ }^{2,3,4}$
}

1 School of Computer Sciences, Universiti Sains Malaysia, 1180o USM Pulau Pinang, Malaysia

2 Chief Editor, Malaysian Journal of Medical Sciences, USM Press, Universiti Sains Malaysia, 1180 o USM Pulau Pinang, Malaysia

3 Center for Neuroscience Services and Research, Health Campus, Universiti Sains Malaysia, 16150 Kubang Kerian, Kelantan, Malaysia

4 Department of Neurosciences, School of Medical Sciences, Universiti Sains Malaysia, 16150 Kubang Kerian, Kelantan, Malaysia

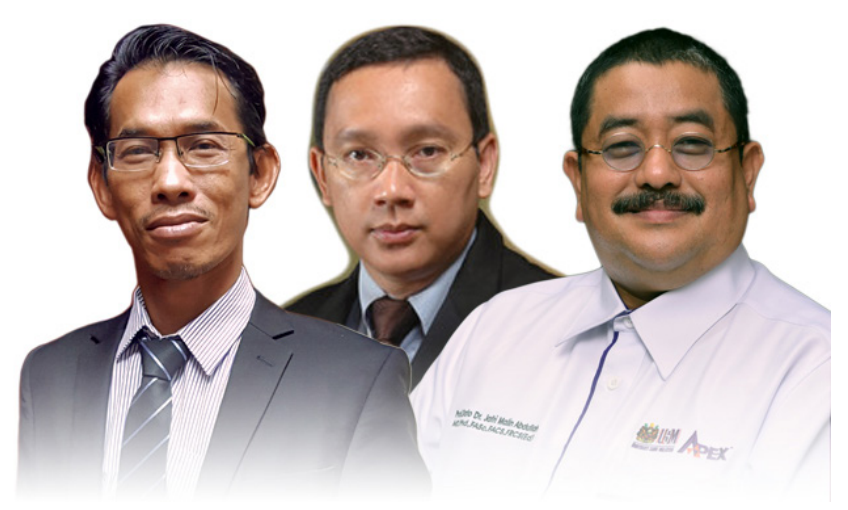

To cite this article: Putra S, Zamzuri I, Jafri Malin A. We must invest in applied knowledge of computational neurosciences and neuroinformatics as an important future in Malaysia: the Malaysian brain mapping project. Malays J Med Sci. 2017;24(1):1-9. https://doi.org/10.21315/mjms2017.24.1.1

To link to this article: https://doi.org/10.21315/mjms2017.24.1.1

\section{Abstract}

The Academy of Sciences Malaysia and the Malaysian Industry-Government group for High Technology has been working hard to project the future of big data and neurotechnology usage up to the year 2050. On the 19 September 2016, the International Brain Initiative was announced by US Under Secretary of State Thomas Shannon at a meeting that accompanied the United Nations' General Assembly in New York City. This initiative was seen as an important effort but deemed costly for developing countries. At a concurrent meeting hosted by the US National Science Foundation at Rockefeller University, numerous countries discussed this massive project, which would require genuine collaboration between investigators in the realms of neuroethics. Malaysia's readiness to embark on using big data in the field of brain, mind and neurosciences is to prepare for the 4th Industrial Revolution which is an important investment for the country's future. The development of new strategies has also been encouraged by the involvement of the Society of Brain Mapping and Therapeutics, USA and the International Neuroinformatics Coordinating Facility.

Keywords: big data, computational neurosciences, neuroinformatics, neurotechnology, Malaysia, industrial revolution, brain mapping 
To prepare for the 4th Industrial Revolution (4IR) (1), Malaysian neuroscientists must concentrate on engaging in analytics of big data collected on the human neuron system using computational neurosciences and neuroinformatics. Computational neurosciences previously defined as the study of brain functions concerning the information-processing properties of the structures that make up the nervous system must link with the diverse fields of neurosciences, cognitive sciences and psychology with electrical engineering, chemistry, mathematics and physics. Moreover, it is different from machine learning and depends on data derived from resting and active biological neurons and other cells, namely astrocytes for their temporal-spatial electrophysiology, as well as their chemical "characteristics". These data are collected using advanced neurotechnology equipment, such as high-density-array electroencephalography, functional magnetic resonance imaging, near infrared spectroscopy, magnetoencephalography and other devices that both stimulate and record the response of neural tissues.

The Academy of Sciences Malaysia (ASM) and the Malaysian Industry-Government group for High Technology (MIGHT) has worked over the past 2 years to project the future of big data and neurotechnology usage up to the year $2050(2,3)$. The International Brain Initiative was announced by US Under Secretary of State Thomas Shannon at a meeting that accompanied the United Nations' General Assembly in New York City on the 19 September 2016. This initiative was seen as an important effort but deemed costly for developing countries. At a concurrent meeting hosted by the US National Science Foundation at Rockefeller University, numerous countries discussed this massive project, which would require genuine collaboration between investigators in the realms of neuroethics (4). Looking at these ongoing global perspectives, it is about time that ASM and MIGHT unite Malaysian neuroscientist so as to achieve these knowledge skills and technology to join the 4IR.

Computational neuroscience and neuroinformatics represent growing fields in Malaysia which are important for the growth of Brain Mapping as highlighted by the Society for Brain Mapping and Therapeutics and the International Neuroinformatics Coordinating Facility (INCF) (5). Both focuses on understanding the human brain, the most complex computer system in existence. Computational neuroscience and neuroinformatics are two distinct (with some overlapping) areas, and yet they complement each other. Computational neuroscience is a research field concerned with theoretical methods of investigating the function and mechanism of the nervous system. It aims to give a quantitative description of functionality and biologically realistic neuron networks and to capture them in realistic models that can be used to develop new hypotheses to be experimentally tested. This field is also often loosely referred to as computational modelling. To continue deepening our understanding of the brain, it is necessary for many and various sub-disciplines to share data and findings in a meaningful way. In contrast, neuroinformatics is a research field concerned with the organisation of neuroscience data via the application of databases and analytical tools. Such areas of research are important for the integration, sharing, management and analysis of increasingly large-volume, high-dimensional, and finegrain experimental data. This field provides computational tools, mathematical models and interoperable databases for research scientists.

Scientific endeavours in the computational neuroscience and neuroinformatics fields have been ongoing for centuries. Today, the advance of technology has led to the point where we can understand brain function perhaps down to the molecular level; however, Malaysia still has a long way to go to fulfil the goal of understanding basic brain function. The future of computational neuroscience and neuroinformatics are wide open in Malaysia, and the directions that remain to be explored in the development of methods, techniques and algorithms are described below (6).

Data archiving is used to efficiently collect, store, query and share neuroimaging data. Some of these data are large in scale (big data), geographically distributed and already have a large dataset and a well-established user community. To engage in data archiving, it is also necessary to apply a new infrastructure, such as cloud technology, that provides a globally integrated view of the data. Another approach is data visualisation, which facilitates viewing and understanding the context of brain data (7). Three-dimensional (3D) visualisation and virtualisation for the human brain is the best approach to meeting domain-specific needs. As important equipment, high-performance machines with heterogeneous environments are required to rapidly carry out large-scale 
Editorial | Malaysia brain mapping project

parallel data-processing tasks. This is necessary for the efficient processing of high-volume datasets, especially when a popular bottom-up explorative data analysis (8) approach is used. Furthermore, data mining is an approach used to efficiently extract meaningful information from the data; this represents the most challenging part of computational neuroscience and neuroinformatics advancement. Machine learning and statistical software are crucial requirements for the success of data mining. Data modelling is also necessary, as it provides a link between the data we collect and our theories about the way the brain works. This approach provides a scaffold for collecting data of interest and acts as a proving ground for theories. Software package tools facilitate the analysis of heterogeneous datasets for a better understanding the structure and function of the brain. Such tools enhance data collection, sharing, storage, manipulation, analysis, integration, interpretation, modelling and collaboration. Tools can be used to run largescale simulations and helping scientists to carry out difficult and time consuming tasks. Braincomputer interface (BCI) prototype development is necessary to generate intelligent technical devices with brain-inspired sensors that carry out a complex task in a safe, reliable way. Finally, strategic collaboration between many parties, such as clinicians and researchers, should be fostered to understand the brain. The US BRAIN Initiative (9) and BLUE Brain project (10) are some examples of collaboration. The future is heavily dependent on a new spirit of working together as a global community.

The growth of neurosciences in Malaysia, audited using Scopus data (Figure 1-6), indicates that the investment of neurosciences in research universities in Malaysia are focused mainly on general neurosciences and that neuroscientists are mostly working in silos. This needs to change if we are to join the Global Brain Project.

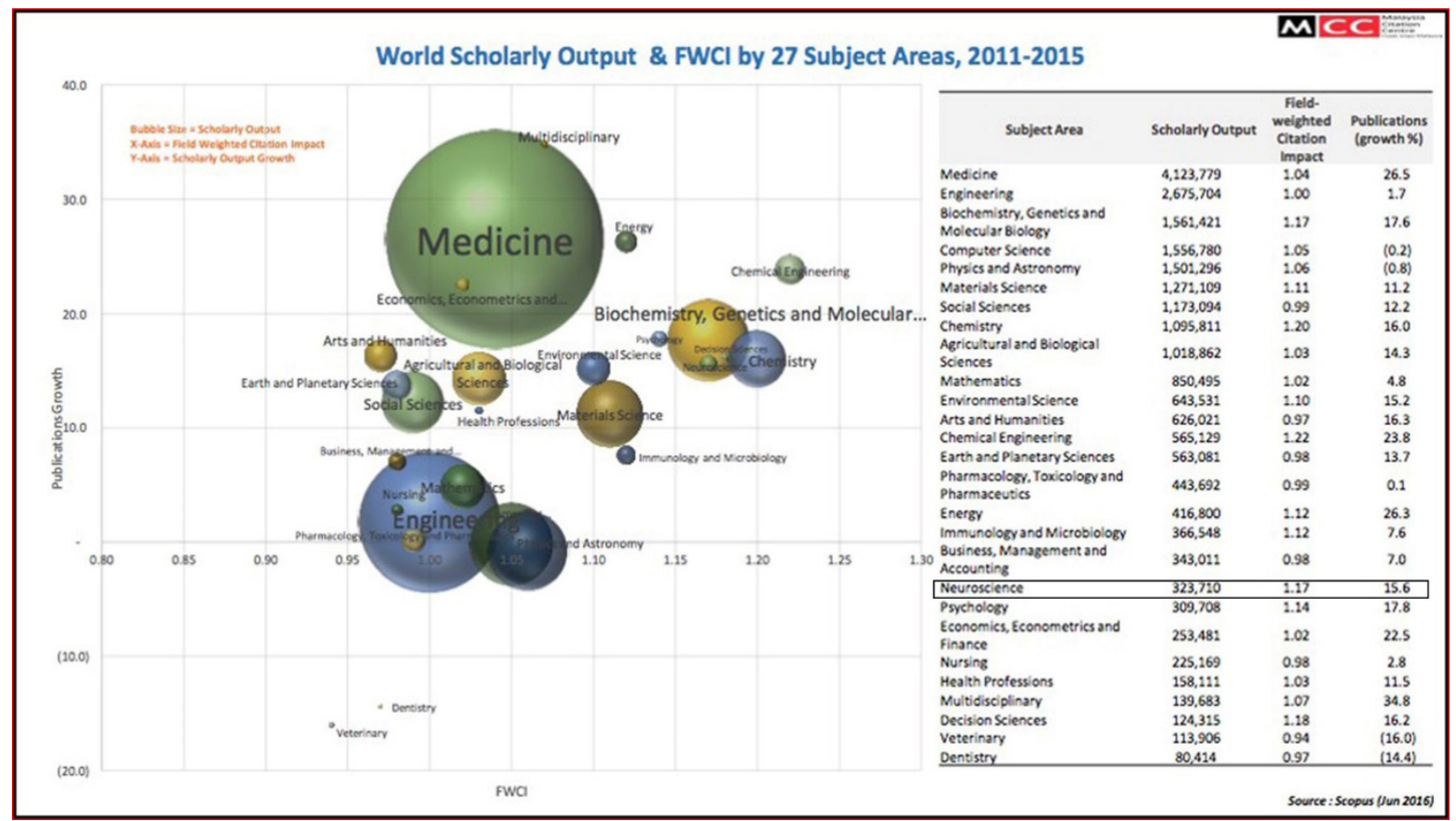

Figure 1. The field-weighted citation impact (FWCI) of neuroscience (worldwide) is 1.17, which is very good compared to other subjects (black square). The FWCI world average is 1.o. The publication growth rate for neuroscience is $115.6 \%$ ( 5 years) 


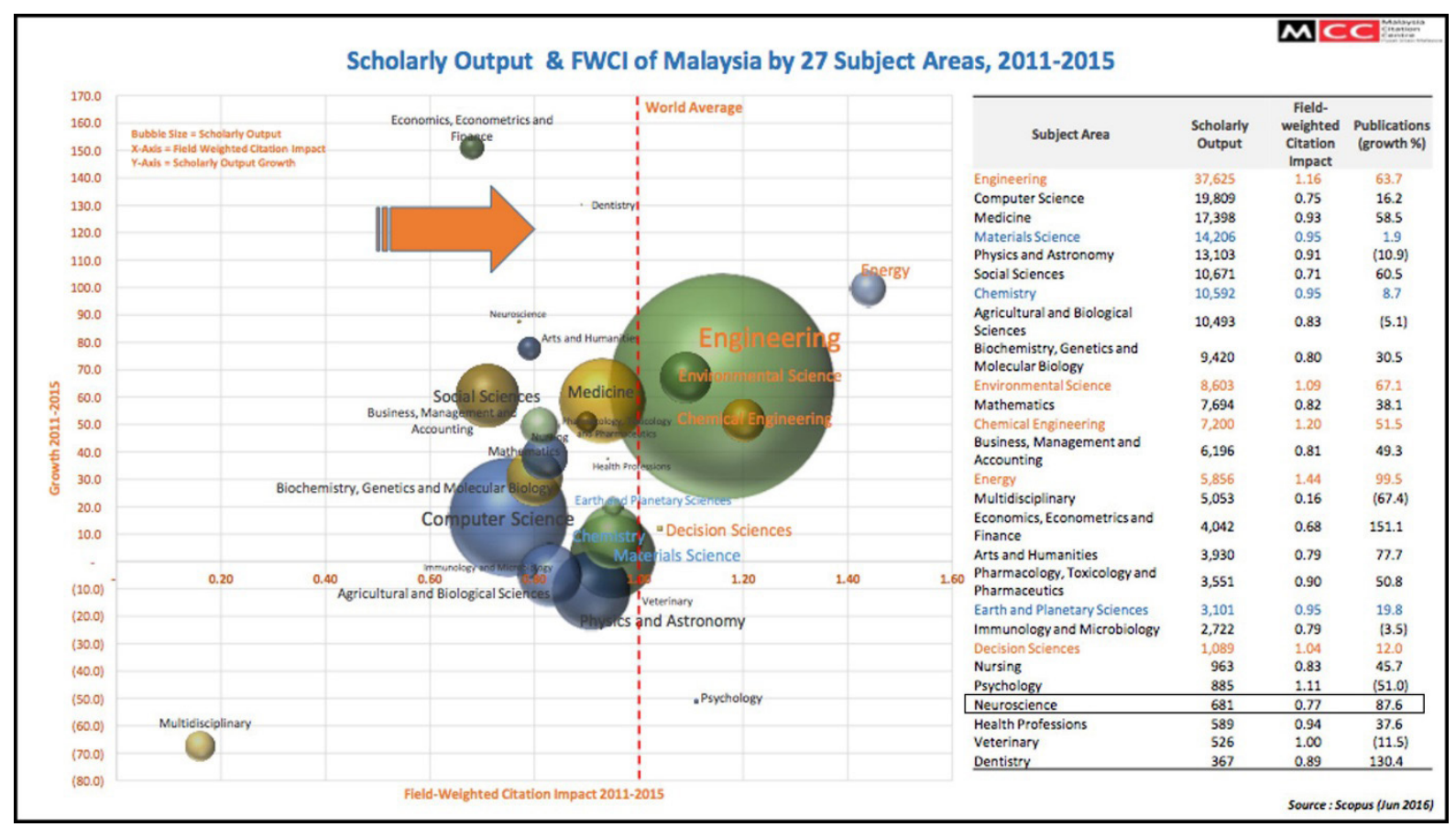

Figure 2. The field-weighted citation impact (FWCI) of neuroscience in Malaysia is < 0.8 (black square). The FWCI world average is 1.o. The percentage growth of Malaysian neuroscience $(<90 \%)$ is below the world average (100\%). However, the result is good compared to other subject areas in Malaysia

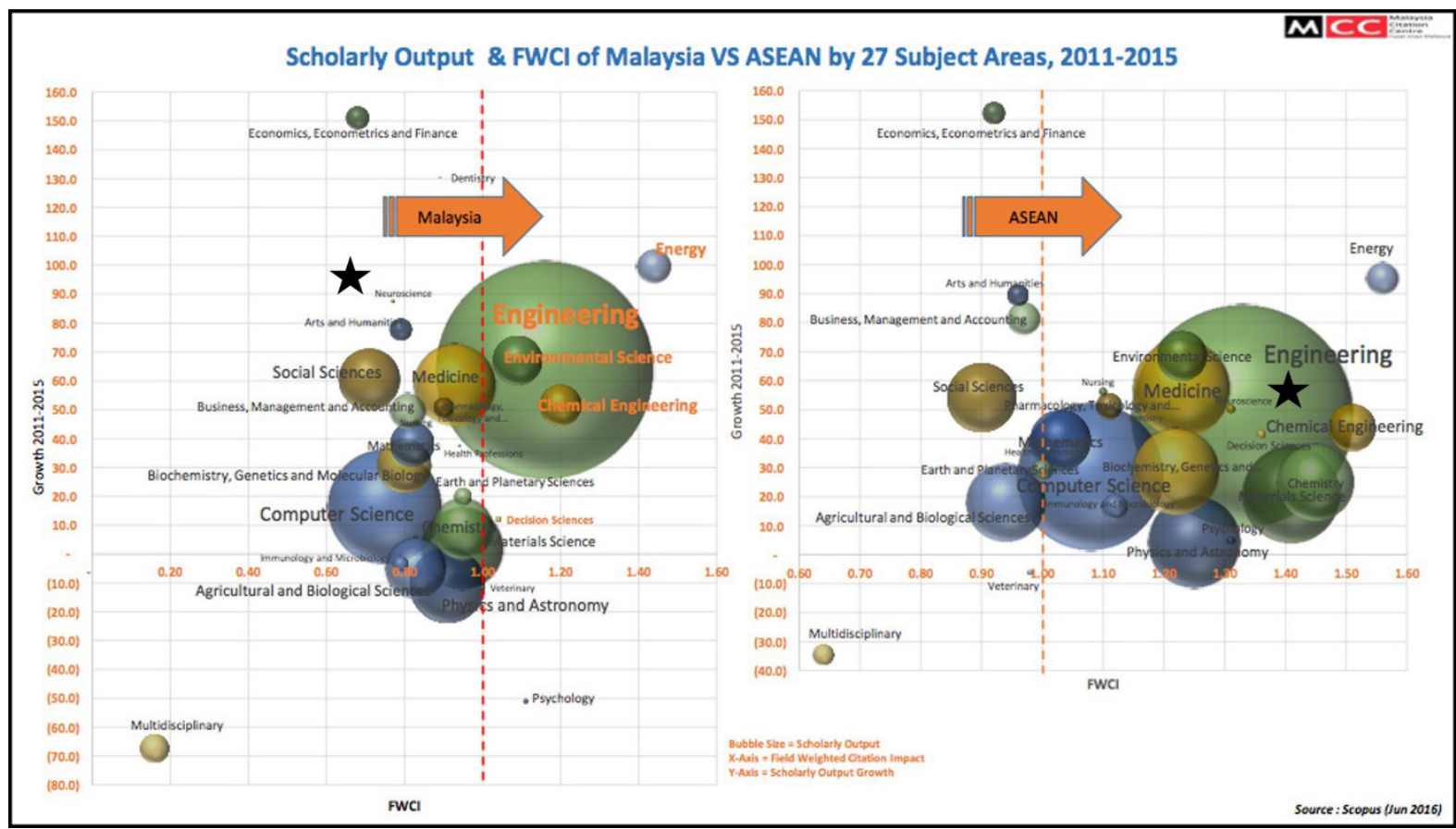

Figure 3. Neuroscience in Malaysia is below the world's average in terms of growth and FWCI (black star). Neuroscience in ASEAN is above the world's average in terms of FWCI but exhibits much slower growth (black star) 
Editorial | Malaysia brain mapping project

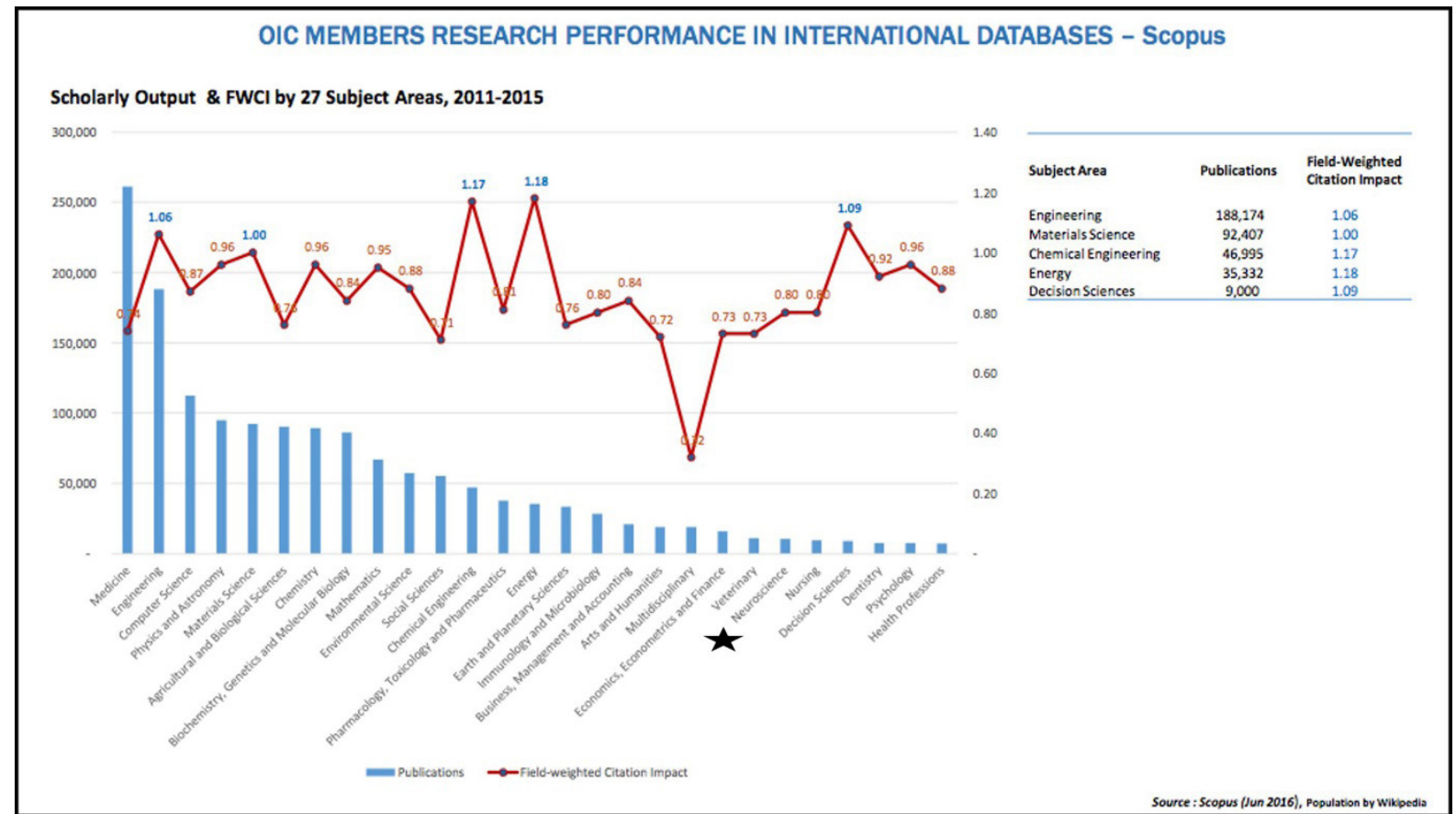

Figure 4. Performance of neuroscience in OIC member countries (o.8) is below the world's average (1.0) in terms of FWCI (black star)

\begin{tabular}{|c|c|c|c|c|c|c|c|c|}
\hline & \multicolumn{7}{|c|}{ RU's Publications by Subject Area Ranked by FWCI, 2011-2015 } & 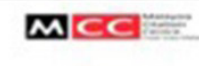 \\
\hline & Subject Area & Publications & $\begin{array}{l}\text { Publications } \\
\text { (erowth X) }\end{array}$ & Clations & Authors & $\begin{array}{l}\text { Authors } \\
\text { (erowth } x \text { ) }\end{array}$ & $\begin{array}{l}\text { Cestions per } \\
\text { Publication }\end{array}$ & $\begin{array}{l}\text { Feld welehted } \\
\text { Citation } \\
\text { Impagt }\end{array}$ \\
\hline 1 & Energy & $3 \mathrm{An}$ & 91.5 & 34599 & 4.125 & 12000 & 100 & $1 \pi 7$ \\
\hline 2 & Declision Sciences & 547 & 327 & 2,435 & $\operatorname{sen}$ & 38.5 & 4.5 & 2.45 \\
\hline 3 & Oremical Engineering & 5.376 & 379 & 41.825 & 6.238 & ses & 7.8 & 123 \\
\hline 4 & Englneering & 21,028 & 51.8 & 68,324 & 18.177 & $n 2.2$ & 3.3 & 1.20 \\
\hline s & Environmental Sclence & $5 s e 4$ & 499 & 35,285 & 7,483 & 69.8 & 6.0 & 1.18 \\
\hline 6 & Dentistry & 235 & 543 & 888 & 365 & 68.1 & 3.8 & 1.18 \\
\hline 7 & Pyvehology & 564 & -61.9 & 2.681 & 1.062 & 64.4 & 30 & 108 \\
\hline 8 & Earth and Planetary Sciences & 1926 & 25.6 & 7,317 & 2236 & 23.3 & 3.8 & 206 \\
\hline 9 & Health Professions & 401 & 297 & 2.506 & 688 & 47.3 & 3.8 & 205 \\
\hline 20 & Materials Solence & 10,291 & -260 & 52,787 & 8.025 & 35.3 & S.1 & 0.97 \\
\hline i1 & Chemisty & 8.407 & .73 & 54.973 & 7,036 & 56.3 & 65 & 0.93 \\
\hline 12 & Physics and Astronomy & 9.881 & -294 & 39.945 & 7.621 & 16.2 & 40 & 0.92 \\
\hline 13 & Mathematics & 4.596 & 225 & 12.001 & 4.879 & 42.4 & 26 & 0.91 \\
\hline 14 & Pharmacology, Toxicology and Pharmaceutics & 2.371 & 20.1 & 12.396 & 3,452 & 35.2 & 5.2 & 0.91 \\
\hline is & Business, Management and Accounting & $3,08 s$ & 59.3 & 6.317 & 3,700 & 31.8 & 20 & 0.90 \\
\hline 26 & Medicine & 12847 & 60.8 & 54336 & 15,183 & ros & 4.2 & 0.89 \\
\hline 17 & Veterinary & 488 & 5.2 & 1.247 & 796 & 26.2 & 28 & 0.89 \\
\hline 18 & Computer Science & 10,174 & 15.1 & 24,871 & 9,733 & 215 & 24 & 0.87 \\
\hline 19 & Agricultural and Biological Sciences & 7598 & -203 & 30,556 & 9.564 & 125 & 40 & 0.82 \\
\hline 20 & Arts and Humanities & 2542 & 1124 & 2.603 & 3,231 & 117.7 & 10 & 0.82 \\
\hline 21 & Neurosciense & 489 & 853 & 2441 & 84 & 1086 & 50 & 0.82 \\
\hline 22 & Bochemistry, Genetics and Molecular Biology & 7214 & 218 & 38.275 & 10.234 & 34.4 & 5,3 & 0.79 \\
\hline 3 & Nursing & 681 & 520 & 2.327 & 1341 & 56.8 & 34 & 0.79 \\
\hline 24 & Immunology and Microbiology & 2,165 & -5.1 & 10,431 & 3,605 & 6.8 & 4.9 & 0.76 \\
\hline 25 & Social sciences & 6,391 & 618 & 8,519 & 7,352 & 62.6 & 23 & 0.75 \\
\hline 26 & Economiks, Econometriks and Finance & 2418 & 2646 & 3,122 & 2862 & 185.6 & 23 & 0.67 \\
\hline 27 & Multidisciplinary & 3.502 & -631 & 7,120 & 5.954 & 45.0 & 20 & 0.15 \\
\hline
\end{tabular}

Figure 5. Neuroscience is ranked 21 amongst 27 subject areas in Malaysia (red square) 


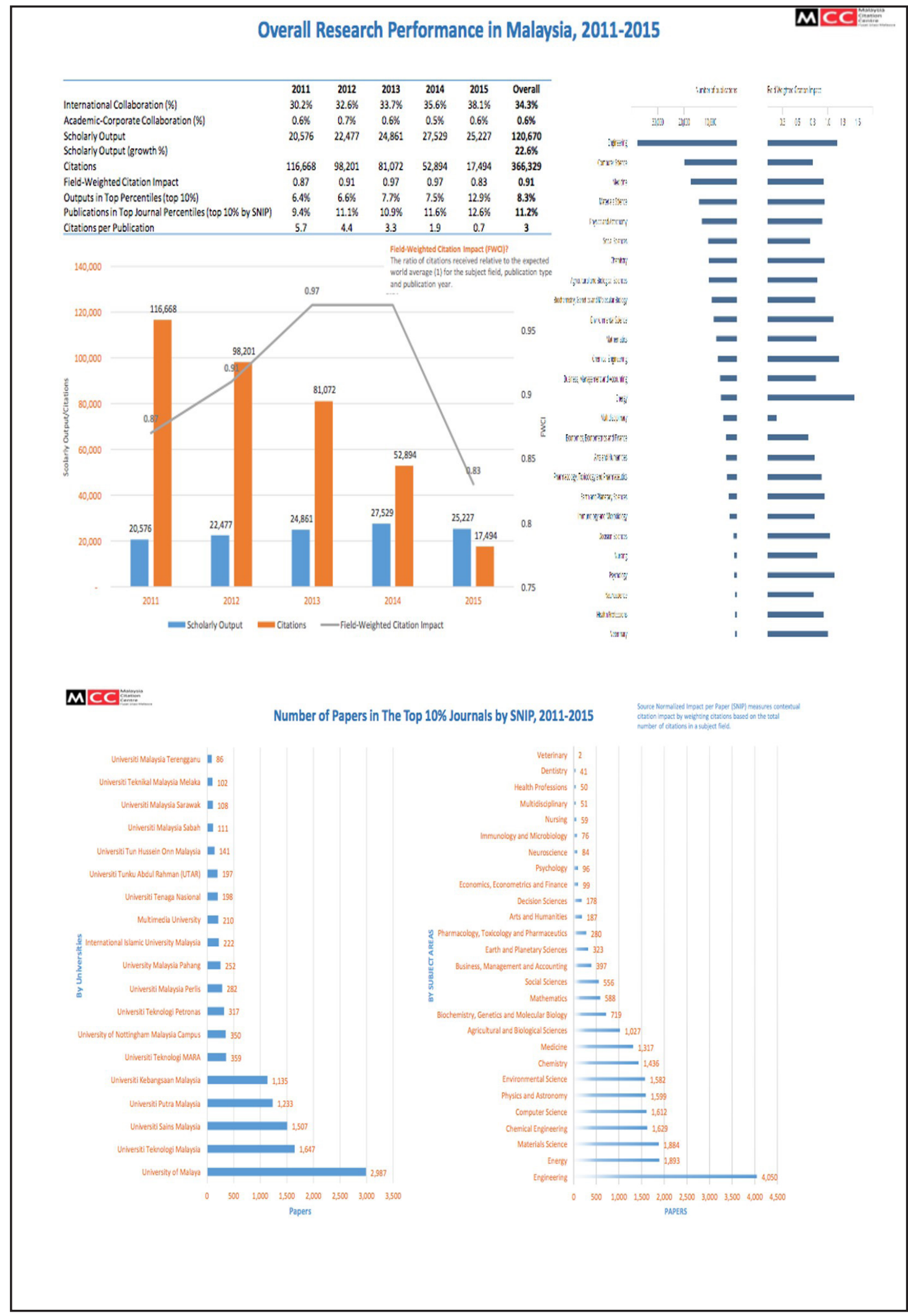

Figure 6. Although the number of papers published in neuroscience in Malaysia is small compared to others, the field-weighted citation impact (FWCI) is good (o.82) but below the world average of 1.0 
Editorial | Malaysia brain mapping project

Recent articles from the journal Neuron in $2016(11-32)$ indicates that countries like Malaysia must invest in trans-university and translational efforts with the support of human ethical approval to collect, store and analyse data from humans in states of both wellness and illness to find common effective cures or preventive measures. This will boost both the number of translational data analyses in the field of neuroscience and create at least 10 cognitive scientist in these fields per 100,000 labour force workers by 2025 for Malaysia to enter the 4th Industrial Revolution.

The sharing of data from numerous institutions in the scientific fields mentioned above are crucial (33). Common big data are needed to determine which signal biomarkers from computational neurosciences are important. With the unified support from the Ministry of Health, Ministry of Science, Technology and Innovation and Ministry of Higher Education; such data can be used to ensure that Malaysia achieves a healthy population by 2050 in both mind and body. It is important for a Malaysian brain, mind and neuroscience initiative to be developed as a national project namely "The Malaysian Brain Mapping Project”.

\section{Authors' Contributions}

Conception and design: PS, ZI, JMA

Analysis and interpretation of the data: JMA

Drafting of the article: PS, ZI, JMA

Critical revision of the article for important intellectual content: PS, ZI, JMA

Final approval of the article: PS, ZI, JMA

Administrative, technical, or logistic support: PS, ZI, JMA

Collection and assembly of data: PS, ZI, JMA

\section{Correspondence}

Professor Dato' Dr. Jafri Malin Abdullah MD, PhD, DSCN (Belgium), FRCS (USA), FRSM (UK), FACs

Chief Editor

Malaysian Journal of Medical Sciences

USM Press, Universiti Sains Malaysia

11800 USM Pulau Pinang,

Pulau Pinang, Malaysia

Tel: +604 6534420

E-mail: mjms.usm@gmail.com

\section{References}

1. Schwab K. The fourth industrial revolution: what it means, how to respond. World Economic Forum. 2016. https://www.weforum.org/ agenda/2016/01/the-fourth-industrialrevolution-what-it-means-and-how-to-respond/

2. Malaysian Foresight Institute. The foresight Malaysia 2050 report. Academy Science Malaysia, Ministry of Science Technology and Innovation. 2016. In Press.

3. Malaysian Industry-Government Group for High Technology. The 8 technology values. 2016 https://www.might.org.my/download/the-8technology-values

4. Reardon S. Global Brain Project Sparks Concern. Nature. Macmillan Publishers Limited. 2017. https://dx.doi.org/10.1038/nature.2016.20658

5. Jafri Malin A. Another important news from the neuroman: Malaysia's neuroscience group moves upwards in terms of research creativity and innovation. Malays J. Med Sci. 2015;22(Spec Issue): $1-4$

6. Cheng X, Marcus D, Van Horn JD, Luo Q, Mattay VS, Weinberger DR. Going beyond the current Neuroinformatics infrastructure. Front. Neuroinform. 2015;9:15. https://dx.doi. org/10.3389/fninf.2015.00015

7. Gutman DA, Dunn WD Jr, Cobb J, Stoner RM, Kalpathy-Cramer J, Erickson B. Web based tools for visualizing imaging data and development of XNATView, a zero footprint image viewer. Front. Neuroinform. 2014;8:53. https://dx.doi. org/10.3389/fninf.2014.00053

8. Eklund A, Dufort P, Villani M, LaConte S. BROCCOLI: Software for fast fMRI analysis on many-core CPUs and GPUs. Front. Neuroinform. 2014;8:24. https://dx.doi.org/10.3389/fninf. 2014.00024

9. INTERIM REPORT. Brain research through advancing innovative neurotechnologies (BRAIN) working group. 2013. http://braininitiative.nih. gov/pdf/09162013_interim_report_508C.pdf

10. Markham H. The blue brain project. Nat Rev: Neuroscience. 2006;7(2):153-160. https:// dx.doi.org/10.1038/nrn1848 
11. Brose K. Global neuroscience. Neuron. 2016;92(3):557-558. https://dx.doi.org/10. 1016/j.neuron.2016.10.047

12. Levitt P, Carey M, Ramirez S, Dzirasa K, Luca MD. Supporting the next generation of neuroscientists. Neuron. 2016;92(3):559-560. https://dx.doi.org/10.1016/j.neuron.2016.10.041

13. Fairhall A, Svoboda K, Nobre AC, Gradinaru V, Nusser Z, Ghosh A, Tsien R. Global collaboration, learning from other fields. Neuron. 2016;92(3):561-563. https://dx.doi. org/10.1016/j.neuron.2016.10.040

14. Ting A, Segal R, Carandini M, Emiliani V, Yizhar O, Roska B, Ji N, Anderson DJ. Opportunities for technology and tool development. Neuron. 2016;92(3):564-566. https://dx.doi.org/10. 1016/j.neuron.2016.10.042

15. Schinder AF, Bonhoeffer T, Sperling R, Dudai Y, Marin O, Morris R, Mrsic-Flogel T. Organizing brain science on an international Scale. Neuron. 2016;92(3):567-569. https://dx.doi. org/10.1016/j.neuron.2016.10.043

16. Martin CL, Chun M. The BRAIN initiative: Building, strengthening, and sustaining. Neuron. 2016;92(3):570-573. https://dx.doi. org/10.1016/j.neuron.2016.10.039

17. Amunts K, Ebell C, Muller J, Telefont M, Knoll A, Lippert T. The human brain project: Creating a European research infrastructure to decode the human brain. Neuron. 2016;92(3):574-581. https://dx.doi.org/10.1016/j.neuron.2016.10.046

18. Okano H, Sasaki E, Yamamori T, Iriki A, Shimogori T, Yamaguchi Y, Kasai K, Miyawaki A. Brain/MINDS: A Japanese National Brain project for Marmoset neuroscience. Neuron. 2016;92(3):582-590. https://dx.doi.org/10. 1016/j.neuron.2016.10.018

19. Poo M-M, Du J-L, Ip NY, Xiong Z-Q, Xu B, Tan T. China brain project: Basic neuroscience, brain diseases, and brain-inspired computing. Neuron. 2016;92(3):591-596. https://dx.doi. org/10.1016/j.neuron.2016.10.050

20. Australian Brain Alliance Steering Committee. Australian brain alliance. Neuron. 2016;92(3):597-600. https://dx.doi.org/10. 1016/j.neuron.2016.10.038
21. Jabalpurwala I. Brain Canada: One brain one community. Neuron. 2016;92(3):601-606. https://dx.doi.org/10.1016/j.neuron.2016.10.049

22. Jeong S-J, Lee H, Hur E-M, Choe $\mathrm{Y}$, Koo JW, Rah J-C, et al. Korea brain initiative: Integration and control of brain functions. Neuron. 2016;92(3):607-611. https://dx.doi. org/10.1016/j.neuron.2016.10.055

23. Koch C, Jones A. Big science, team science, and open science for neuroscience. Neuron. 2016;92(3):612-616. https://dx.doi. org/10.1016/j.neuron.2016.10.019

24. Wiener M, Sommer FT, Ives ZG, Poldrack RA, Litt B. Enabling an open data ecosystem for the Neurosciences. Neuron. 2016;92(3):617-621. https://dx.doi.org/10.1016/j.neuron.2016.10.037

25. Neuro Cloud Consortium. To the cloud! A grassroots proposal to accelerate brain science discovery. Neuron. 2016;92(3):622-627. https:// dx.doi.org/10.1016/j.neuron.2016.10.033

26. Bouchard KE, Aimone JB, Chun M, Dean T, Denker M, Diesmann M, et al. High-performance computing in neuroscience for data-driven discovery, integration, and dissemination. Neuron. 2016;92(3):628-631. https://dx.doi. org/10.1016/j.neuron.2016.10.035

27. Nishi R, Castaneda E, Davis GW, Fenton AA, Hofmann HA, King J, et al. The global challenge in neuroscience education and training: The MBL perspective. Neuron. 2016;92(3):632-636. https://dx.doi.org/10.1016/j.neuron.2016.10.026

28. Greely HT, Ramos KM, Grady C. Neuroethics in the age of brain projects. Neuron. 2016;92(3):637-641. https://dx.doi.org/10. 1016/j.neuron.2016.10.048

29. Garden H, Bowman DM, Haesler S, Winickoff DE. Neurotechnology and society: Strengthening responsible innovation in brain science. Neuron. 2016;92(3):642-646. https://dx.doi. org/10.1016/j.neuron.2016.10.053

30. Sinha P. Neuroscience and service. Neuron. 2016:92(3):647-652. https://dx.doi. org/10.1016/j.neuron.2016.10.044

31. Bennett AJ, Ringach DL. Animal research in neuroscience: A duty to engage. Neuron. 2016;92(3):653-657. https://dx.doi.org/10. 1016/j.neuron.2016.10.034 
Editorial | Malaysia brain mapping project

32. Roskams J, Popovic Z. Power to the people: Addressing big data challenges in neuroscience by creating a new cadre of citizen neuroscientists. Neuron. 2016;92(3):658-664. https://dx.doi. org/10.1016/j.neuron.2016.10.045
33. Grillner S, Ip N, Koch C, Koroshetz W, Okano $\mathrm{H}$, Polachek M, et al. Worldwide initiatives to advance brain research. Nat Neuroscience. 2016;19:1118-1122. https://dx.doi.org/10.1038/ nn.4371 